\title{
A violência dos limites na arte
}

\section{Sérgio Rojas}

\author{
Universidad de Chile \\ Santiago de Chile, Chile \\ sergiorojas_s21@yahoo.com.ar \\ orcid.org/0000-0002-2143-6079
}

\begin{abstract}
La violencia de los limites en el arte
Resumen I Planteo en este artículo la pregunta por la posibilidad que ten-dría hoy el arte de abordar la violencia, cuando ya es manifiesto que esta no opera como excepcional interrupción de la cotidianeidad, sino que toma cuerpo en esta. Lo que intento refle- xionar no es el modo en que las artes hacen de la violencia un "tema", sino la posibilidad de que esta sea pensada, que el destinatario de las obras será alterado no por el espectáculo de la vio-lencia, visibilizada en hechos de sangre, sino por lo abrumador que resulta lle- gar efectivamente a pensar en el orden de la violencia. Que no sea

el primer plano de una carnicería humana lo que enmudece haciendo faltar las palabras, sino el pensamiento que la violencia provoca en el espectador a partir de una circunstancia artística. La hipótesis principales que con relación a la vio-lencia los propios límites instituidos del arte pueden constituirse en un recurso tan ambiguo como esencial para dar lugar a ese pensamiento.
\end{abstract}

PALABRAS CLAVE Arte. Violência. Cuerpo.

The violence of art's limits

Abstract | I ask about the possibility of art to face violence today when it is clear that it is not an exceptional interruption of life but an intrinsic part of it. I am not trying to think about how art uses violence as a "theme," but the possibility for it to be reflected upon. I am not interested in the spectator being moved by violence's bloody spectacle, but how crushing it might be to think in violence's terms. Not a carnage that mutes, but one that provokes thought amid an artistic experience. The central hypothesis is that art's limits may become an ambiguous and essential resource that give rise to thought concerning violence.

KEYWORDS: Art. Violence. Body.

Enviado em: $23 / 11 / 2020$

Aceito em: $18 / 12 / 2020$

Publicado em: 23/12/2020 para dar origem a esse

pensamento.

PALAVRAS-CHAVE: Arte. Violência. Corpo. 
"O espectador está seguro em terra firme porque é capaz dessa distância, sobrevive graças a uma de suas qualidades inúteis:

poder ser espectador"

Hans Blumenberg ${ }^{1}$

Ao analisar o fenômeno da violência, enfrentamos atualmente um paradoxo triplo. Primeiro, nunca houve uma consciência tão difundida sobre o valor da vida humana, porém antes não tínhamos tanta riqueza de informações sobre as violações da vida de todas as formas imagináveis. Segundo, a paz não se opõe mais à guerra, mas se transforma em ações e processos de pacificação, que implica a coexistência com situações de violência estrutural. Terceiro, todas as pessoas dizem apreciar a democracia, mas são poucas as que realmente acreditam nela. Isso nos leva a pensar que hoje a violência não é uma situação de "exceção", mas de alguma forma a ordem do mundo. Como consequência, tem-se a sensação de que não há alternativas, de que "não há saída".

Nesse sentido, nas práticas artísticas que se propõem a enfrentar a violência surge um desejo de radicalismo ao questionar códigos de autonomia da institucionalidade da arte. Este artigo se propõe a questionar se existem limites que são essenciais para a arte, tanto para seu status quanto para seu poder reflexivo. Para tanto, o que se busca refletir não é se a produção artística deveria considerar algum tipo de senso moral ou ético como limite a priori de seu campo de possibilidades; mas refletir se os limites poderiam ser um recurso para o pensamento artístico, ou seja, os limites nos quais as operações artísticas permanecem compreensíveis como arte, enfrentando um problema que requer recursos extremos como a violência. Isso resulta no título deste artigo: não os limites "da" arte, mas na arte.

Muitas vezes, a radicalidade nas práticas artísticas que abordam a violência é exigida pelo imperativo de confronto entre o espectador e os efeitos da violência; dessa forma, os corpos exibem traços de algo maior, a vida nua, isto é, como o corpo de uma vida completamente exposta, em que o levinasiano "não me mate" já se transformou em um processo sem-fim de destruição. Os corpos apresentam vestígios de uma agressão que não reconhece a vida como limite, aqui a violência se concretiza em vítima. Frequentemente, vemos que nas artes cujo tema é a violência, o objeto não é o perpetrador da violência, mas as vítimas, os corpos das vítimas. O problema é se uma obra sobre violência ao mesmo tempo pode refletir sobre isso, ou seja, pensar no que há de extraordinário além dos recursos que silenciam o espectador. Uma hipótese é que pensar sobre a ordem da violência requer refletir sobre a forma como ela se torna parte da "ordem de um mundo", ou seja, não bastaria apenas ver sua terrível irrupção, em que os corpos se transformam em vestígios de uma vontade de destruir que não cabe no mundo, mas de pensar

${ }^{1}$ Hans Blumenberg: Naufragio con espectador. Paradigma de una metáfora de la existencia, Madrid, Visor, 1995, p. 26. 
como é possível habitar a violência. Isso implica considerar outras formas de fazer o real adentrar no espaço-tempo das práticas artísticas como referência a um acontecimento a partir da arte e como um acontecimento na arte. Dessa forma, expõe-se a possibilidade de uma recuperação crítica da representação.

A performance pode implicar um impasse no espaço-tempo cotidiano, uma suspensão da representação, uma fissura na cena. "De repente [escreve Diana Taylor] um ato corporal espontâneo que perturba o cotidiano pode ser visto como uma performance de resistência à censura" (TAYLOR, 2011, p.11). O núcleo dessa atuação é o acontecimento, que evoca a questão da temporalidade que isso acarreta. A questão essencial colocada aqui não se refere diretamente ao conteúdo, mas à realidade que vai além do espaço-tempo da representação. 0 espaço cênico da representação não é apenas uma "mediação" que supostamente seria necessário superar para corresponder à pretensão de assistir ao acontecimento em sua desnudez semântica. A representação em si como marco, e tudo o que isso implica, é necessária no processo de fazer-acontecer do espectador sobre a realidade daquilo que é relatado ou referido, o fato de que algo que emerge em cena não nasceu dali. O cerne da questão é o que acontece no decorrer da narrativa. Portanto, o confronto essencial não reside na diferença entre a representação que ocorre no espaço da arte e a realidade daquilo que é representado (uma informação que sempre é possível acrescentar), mas na tensão que se produz entre representação e acontecimento.

Qual é o sentido de trazer a violência para o espaço da representação? Para essa questão três noções podem ser fundamentais: evento, representação e espectador. De início, a representação neutraliza esteticamente a violência organizando-a como objeto (de consumo, de curiosidade, de informação etc.) para o espectador. Por outro lado, as condições com as quais o espectador se depara com a representação artística (ou seja, essa especial circunstância instituída que é a arte, por exemplo caminhando por uma galeria ou sentado em uma sala de teatro) fazem com que ele se disponha a ser surpreendido por uma intensidade que coloca em "perigo" os códigos da distância contemplativa. Uma estranha percepção de que "isso é arte, porém o que acontece aqui está a ponto de extrapolar os limites da fronteira da arte". O espectador pode então se sentir tocado por algo que, a partir da obra, questiona o seu próprio lugar de espectador. Que efeito é esse? Não é possível atribuí-lo diretamente à violência como conteúdo temático da obra, uma vez que na história da arte o espetáculo da violência serviu até mesmo para a constituição e intensidade de uma interioridade subjetiva, especialmente quando se trata de conteúdo religioso.

Entre as representações da crucificação de Cristo na história da arte, sem dúvida uma das mais impressionantes é a pintura do bávaro Matthias Grünewald (1450-1530), conhecida como A Crucificação. Nela é como se o artista tentasse reproduzir a imagem da dor extrema, ou melhor a imagem de um corpo com dor extrema. Como aponta Joris-Karl Huysmans em um texto notável, o resultado é "o corpo devastado de um Deus" (HUYSMANS, 1905, p.60). Como o espetáculo daquele corpo torturado remete transcendência ao espectador? Que tipo de 
rigor Grünewald utiliza na produção desta obra? A exacerbação visual do martírio em um corpo com sofrimento levou a própria imagem ao limite de suas possibilidades de significações. A cruz é a estrutura desse corpo, de tal forma que Cristo na cruz é a representação de Cristo. Isso permite que o espectador se detenha nos vestígios da dor, como se o homem sacrificado dissesse da cruz: "Olhe para mim!"

Huysmans descreve a expressão do sacrifício de Karlsruhe:

\begin{abstract}
"Por cima desse corpo vislumbra a cabeça, tumultuada e enorme com uma coroa de espinhos, que pendia exausto por um lado e entreabria apenas um olho pálido, que tremia de dor e horror. 0 rosto era monstruoso, a testa devastada, as bochechas exauridas; todas as feições decompostas choravam, enquanto a boca entreaberta tinha a mandíbula contraída por espasmos atrozes e tetânicos. O suplício tinha sido terrível, a agonia devia aterrorizar a alegria dos algozes em fuga" (HUYSMANS, 1905, p. 57-58).
\end{abstract}

O evento visual que o corpo de Cristo foi capaz de receber aquele castigo, de sentir aquela dor extrema, porque se entregou voluntariamente à tortura, é fundamental para sua transcendência. A crucificação é a consumação da encarnação, ao mesmo tempo a representação é a consumação da crucificação. O corpo do Deus cristão não morre para retornar à sua origem celestial, mas o próprio corpo é seu túmulo na imagem. O corpo de "Deus" não morreu, mas o Deus morreu de corpo.

Nesse caso, a representação da dor confere um sentido subjetivo de transcendência da matéria. Por outro lado, nesse tipo de violência que estamos analisando (violência social, política, criminal) todas as formas de transcendência foram anuladas, colocando o espectador em confronto com a matéria sem transcendência de uma violência que vai além de sua condição de instrumento, ficando relegada a si mesma. As artes podem pensar a violência quando esta se impõe como uma realidade "sem saída"?

Josette Feral alude ao sentido de mediação que a arte recebeu e as questões que essa noção enfrenta, principalmente quando se trata de acontecimentos de extrema violência. De acordo com a tarefa de mediação, o sentido da arte é permitir que o espectador tenha acesso de maneira compreensiva aos fatos que de outra forma seriam simplesmente inconcebíveis. A partir dessa função mediadora, "entre determinados acontecimentos e sua metaforização, entre determinados fatos e seu significado simbólico, mediação também entre o pessoal e o coletivo", a arte possibilita "uma melhor compreensão do mundo que nos rodeia" (FERAL, 2016, p.45). Ou seja, a arte realiza uma espécie de modulação do real, que traz o acontecimento para a linguagem, mas sem acabar neutralizando sua intensidade na forma pura de significado. Nesse sentido, a mediação artística atua a partir da impossibilidade de anular a instância da representação: "o que quer que o indivíduo faça, ele não poderá escapar da representação, mesmo quando tudo for feito para aboli-la. Sobre essa representação, afirmada ou desmontada, repousa a mediação do mundo" (FERAL, 2016 , p.46). Não há acesso ao real "em si", porque ele não existe; em vez disso, tal 
propósito exibe certo descrédito da representação, mas isso não constitui um véu que devemos tirar para ver o que está escondido "do outro lado". Talvez a naturalização da violência, o fato dela entrar no tecido do nosso cotidiano, leve as pessoas a localizarem a violência em um lugar supostamente notável. Isso implica conceber a violência reduzida à sua ocorrência nua e factual para além da ordem que a produz. Como já mencionado, a reflexão da ordem da violência, para além da sua factualidade, faz da representação um recurso fundamental.

Rita Laura Segato em sua obra sobre os assassinatos na Ciudad Juárez, fronteira norte do México, propõe o termo "crimes de poder" para indicar que não se trata apenas de ações violentas perpetradas por indivíduos com personalidade psicopática, mas que constituem a expressão de uma ordem da realidade que é estruturada e opera como um estado paralelo. Tornar inteligível a atrocidade dessa violência requer transcender o espetáculo da crueldade para acessar a ordem de sua inteligibilidade sinistra. Segato argumenta que: "os crimes sexuais não são obra de indivíduos desviantes, doentes mentais ou anomalias sociais, mas expressões de uma profunda estrutura simbólica que organiza nossos atos e fantasias e Ihes confere inteligibilidade" (SEGATO, 2013, p.19). Portanto, os crimes atuam como uma escrita no corpo; a violência não é instrumental, mas expressa uma vontade que, no universo patriarcal, "comunica" a capacidade de infligir uma destruição física, mental e moral sem limites. Isso é o que vem sendo abordado neste artigo: a necessidade de refletir sobre a ordem segundo a qual a violência não pode ser considerada uma exceção, um surto de irracionalidade, mas um regime que se configura no cotidiano.

Em dezembro de 2007, o artista plástico Santiago Sierra expôs uma obra no espaço cultural Matucana 100, em Santiago, Chile. A instalação foi planejada para receber a visitação de apenas 13 pessoas, todas ligadas ao circuito das artes e das políticas culturais do país. Cada um dos visitantes deveria entrar por um longo e escuro corredor, que dava para um palco onde era contemplado das poltronas por 184 imigrantes de nacionalidade peruana. Quando o visitante tentava voltar a seu ponto de origem, o caminho mudava e ele saía pela porta que dava para a rua, onde um monitor agradecia em nome do artista por concordar em participar "da obra". Isso transformava o espectador em uma espécie de "performer", já que o conduzia ao espaço do espetáculo. Desconfortável, procura uma saída porque a obra terminou para ele, porque sabe que aí está tudo que agora pensará durante muito tempo. Reconhecemos o que é irredutível na representação e na condição do espectador, só que agora não mais como um lugar de proteção da experiência, mas um lugar onde reside a ordem da violência ao invés do silêncio brutal diante dos resquícios do horror.

A instância da representação é questionada em relação a um "real violento" quando se assume que a mediação formalizaria e domesticaria a devastação que se deseja que o espectador "vivencie". Como reação à mediação na arte surge o interesse pelo imediatismo, a tentativa de realizar ações de transgressão ou supressão da representação, especialmente no teatro, buscando assim dar origem a um "imediatismo cênico que não deixa a ação real ocorrer em cena e se confunde com a presença absoluta, até mesmo com o acontecimento, pois pode 
ocorrer fora da cena, na vida real" (FERAL, 2016, p.48). A questão essencial aqui é qual sentido a entrada da violência na arte exigiria "constranger" o espectador, no sentido de que são duas formas distintas de violência.

O conflito entre representação e imediatismo do real na arte enfatiza o "conteúdo" do que acontece, mais precisamente a simples oposição supõe que a violência em si é o conteúdo, a violência cuja intensidade sem interrupção seria neutralizada pela mediação da representação (possibilitando distanciamento e análise) ou liberada por um imediatismo cênico (onde o espectador se altera com os acontecimentos assistidos, quando não é "protegido" pela tela de representação). É necessário refletir sobre o pressuposto que está na base do contraste entre representação e imediatismo da violência. É a ideia de que a violência consiste essencialmente em sofrimento da vítima pela ação de um perpetrador. O corpo - atingido, queimado, cortado - adquire um papel terrível como efeito da destruição do humano, ou seja, o corpo como resíduo de uma violência indiferente à morte, deslocada pelo protagonismo sinistro do cadáver. Porém, o acontecimento que em cena constrange o espectador não o confronta com o que é simplesmente irreparável? A violência consiste inteiramente em um fato consumado? $O$ espectador é, afinal, confrontado com sua própria impotência, e se é possível falar de "responsabilidade", esta constitui uma forma inútil de culpa que incumbe essa impotência ao espectador.

A partir de uma perspectiva crítica sobre a obra de Santiago Sierra e Teresa Margolles, María Campiglia levanta a seguinte questão: "Estamos diante de uma arte de denúncia ou estamos testemunhando simplesmente um exercício de violência perpetrado duas vezes no mesmo corpo?" (CAMPIGLIA, 2015). Segundo Campiglia, essas obras são em parte resultado da grande magnitude da violência que dificulta tomar uma posição diante da violência (o que neste artigo é denominado de pensar a violência), sendo a reação uma forma de se submeter a ela. Com base nesse argumento Sierra e Margolles expõe a existência de uma estética de desencanto e impotência:

"Enunciam com absoluta contundência situações de opressão, mas insistem na impossibilidade de mudança, na impotência dos indivíduos e da arte em modificar a realidade social. Afirma que somos todos cúmplices e artífices do sistema vigente e, se podemos, beneficiários" (CAMPIGLIA, 2015, p. 351). Ileana Diéguez também trata desse complexo tema e expõe a necessidade de uma mobilização do pensamento justamente a partir das imagens do terror, contra o que chama de cinismo que vem do "olhar acomodado" (DIÉGUEZ, 2016, p. 87). Porém, como sugere Diéguez, a distância da "dor alheia" é um fator estrutural da ordem da violência, distância que paradoxalmente poderia ser reforçada pela presença irrestrita do real violento.

Feral cita o artista chinês Huang Yong Ping, que propôs a instalação "Teatro do Mundo" ao Centro Pompidou em 1994: sob uma cúpula em forma de tartaruga, gafanhotos, baratas, tarântulas, centopeia, lagartixas, escorpiões se devoravam uns aos outros. A obra foi rejeitada pelo Centro Pompidou. Segundo o próprio artista, o significado dessa instalação era oferecer "um 
microcosmo dos conflitos mundiais". A violência não está no "conteúdo", na selvageria que está acontecendo naquele espaço fechado, mas no fato de que a perspectiva desse "fato" é imposta ao espectador sob o contrato de arte, ou seja, a obrigação de respeitar passivamente a impunidade que os artistas tacitamente apreciam. Essa impunidade instituída funcionaria como um recurso para representar outro tipo de impunidade? No entanto, ao abstrair o conteúdo direto para atender ao seu suposto significado simbólico, não repetimos a indiferença diante da dor no mundo?

Em relação ao tema em questão, é relevante o problema dos limites da arte proposto por certas obras que buscam tratar a crise das possibilidades críticas da arte em sua possibilidade de se referir ao contexto social e político no qual se insere. Diríamos que é justamente sobre isso, refletir sobre aquele lugar estreitando os limites, não apenas para torná-los visíveis, mas sobretudo perguntar quais são esses limites, se ainda há algo que possa ser visualizado como fronteira. La familia obrera (1968), obra do artista argentino Oscar Bony, mostra um trabalhador e sua família sobre uma plataforma. O trabalhador foi contratado por Bony e recebeu o dobro de seu salário habitual para permanecer em exposição durante o espetáculo coletivo Experiencias 68, realizado no Instituto Di Tella em Buenos Aires. Para o teórico chileno Rodrigo Zúñiga, essa obra não é uma crítica da arte ao meio social, mas uma crítica dirigida à própria arte:

Consuma tanto a crítica ao esteticismo da ruptura quanto o novo privilégio cínico da arte (aquele ato expositivo, da demarcação ou enquadramento de qualquer cena, como uma relação estética executada em nome da Arte). Demarcar 'qualquer coisa' como arte: eis a função soberana da ação artística - denuncia a obra, cumprindo essa função. Na verdade, é um privilégio da imunidade o que parece fazer da arte uma prática autoimune" (ZÚÑIGA, 2010, p.42).

Como já mencionado, na arte contemporânea considera-se arte tudo o que é nomeado como "arte", dessa forma, qualquer coisa poderia aparecer em nome da arte. Este princípio é precisamente o que a arte dos limites se propõe a refletir. A questão não era mais "isso é arte?", mas "isso pode acontecer em nome de arte?" A primeira questão é sobre o status de um objeto ou gesto irrelevante que só poderia adquirir valor sob o pretexto da arte. A segunda questiona se "aquilo" que sabemos que acontece pode ocorrer no campo da arte.

O artista Guillermo Vargas Habacuc (Costa Rica) expôs em 2007 um cão de rua, faminto, na Galeria de Arte Contemporânea Códice. A obra chamada Natividad fazia referência a Natividad Canda, uma jovem que foi devorada por dois cães Rottweiler em 2005, e nesta obra apresentava ao público o cão que estava prestes a morrer de fome e sede, o que de fato aconteceu segundo o artista. Em 19 de agosto de 2007, a Galeria divulgou um comunicado que desmentia o artista sobre o fato de ter deixado o animal morrer de fome. Determinadas obras atuam rompendo os limites da autonomia da arte (a instituição 
e os códigos que protegem as obras da dor e do desejo da realidade humana), bem como ampliando os limites do que pode ser considerado arte. Nesse sentido, aqui ressaltamos especialmente que quando o assunto é abordar a violência, a questão dos limites da arte não se refere apenas à alteração dos códigos instituídos de reconhecimento e validação, mas também à própria relação do espectador com a obra se torna uma área de incertezas, às vezes até de desconforto. Em 2001, o artista chileno Marco Evaristti realizou a instalação "Helena y el pescador" no Museu de Arte Contemporânea, em Santiago, Chile. Essa "exposição" apresentava 8 liquidificadores, todos ligados à energia elétrica, com água e um peixinho nadando em cada um deles. O visitante poderia ligar qualquer um dos aparelhos que estraçalharia o peixe. A instalação constrange o espectador ao transformar a relação deste com a obra em uma questão moral: Eu sou o sádico que apertaria o botão ou o juiz que puniria quem quisesse fazê-lo ou o consumidor voyeurista que apenas observa esperando que alguém ligue o aparelho?

A ação ou acontecimento performativo não se propõe a representar a dor do outro, nem simplesmente fazê-la acontecer, mas ultrapassar o limite que os protocolos sociais constituem como mediações que, ao transformar a dor do outro em representação ou registro, tornam o observador justamente em um espectador ou testemunha impotente, restaurando assim o limite sujeito-objeto. Este limite não pode ser ultrapassado se se pretende começar pela anulação da representação. De fato, a intenção do acesso ao real "em si" não aborda o fato de que a violência, em sentido estrito, não é algo que ocorre além da representação. Ao contrário, a violência como destruição sempre ocorre de acordo com procedimentos, protocolos, preconceitos, representações, ideologias. A partir de certas práticas artísticas, o que se tenta fazer acontecer é justamente a violência dessas "formas", que são aquelas que dispõem o corpo como um lugar de destruição infinita. A questão central é de certo modo a violência da representação. Isso é o que não pode ser simplesmente "representado" ou exposto na forma de vida nua.

A consciência dissimulada da fragilidade da ordem social fomenta a chamada autoimunidade: uma obsessão pela segurança que se torna tão intensa e persistente que leva a multiplicar as barreiras na frente do outro. Sartre escreve: "Para os tempos de paz, a sociedade criou prudentemente (...) profissionais malvados. (...) É necessário, efetivamente, que sejam malvados desde 0 nascimento e sem esperança de mudança (...): crianças abandonadas, 'pobres', burgueses oprimidos, lúmpen, arruinados de toda espécie, enfim, todos os miseráveis" (SARTRE, 1967, p. 39-40). Em tempos de paz é preciso acreditar que esses "miseráveis" são sempre poucos. Em um regime normal, obedecendo à ordem estabelecida, a violência é exercida sobre grupos humanos já vulnerados, pessoas que a mesma ordem social marginalizou, desvalorizou ou expulsou. Quando se reconhece que certos tipos de pessoas vivem em uma exterioridade social interna ("inferiores", "invasores", "desviantes" etc.), estas são dispostas como "sacrificais", sendo objeto de violência cotidiana que não só se normaliza, mas que, pelo mesmo motivo, desaparece como violência. Os agentes cotidianos dessa violência, pessoas 
comuns, ignoram desde sua condição de "beneficiados" em que ponto são meios de circulação de uma violência sistêmica que ameaça a si próprios.

Consideremos, por exemplo, o que aconteceu no Chile com a implacável repressão policial exercida sobre os protestos da população a partir de outubro de 2020. Como "forças da ordem", a polícia atua como defensora da autoridade política do Estado no espaço público; por outro lado, como "forças de segurança" atua no contexto do neoliberalismo como proteção de um modo de vida. A defesa da ordem transforma-se no exercício de uma repressão punitiva, porque na verdade é sobre conter na exterioridade aqueles que não puderam entrar ou almejar esse "modo de vida". Nesse caso, o exercício da violência policial não consiste em defender a ordem, mas expulsar da ordem aqueles que não pertencem a ela. Diante isso, a "ordem social" é articulada em torno dessa forma de vida legitimada e legitimadora da violência que a protege não apenas dos perigos que rondam desde o exterior sobre a propriedade dos "beneficiados", mas também e acima de tudo a consciência do mal, ou seja, a consciência de que a destruição do outro é um fator estruturante da chamada "ordem social". Judith Butler argumenta que a precariedade é inerente à própria vida, ao fato de estar vivo, e não apenas uma condição miserável para a qual aqueles que foram despossuídos e abandonados são empurrados. "Afirmar que uma vida é precária requer não só que a vida seja apreendida como vida, mas também que a precariedade seja um aspecto do que se apreende daquilo que se tem de vida" (BUTLER, 2010, p.29). E acrescenta: "Não nascemos primeiro e depois nos tornamos precários, a precariedade coincide com o nascimento propriamente dito" (BUTLER, 2010, p.31). Já no próprio nascimento, a vida humana necessita ser assistida devido à existência da morte. Tanto o conhecimento quanto a tecnologia dispostos a fim de fazer viver são cada vez mais eficientes e sofisticados, percebendo assim que a vida tornou-se um valor muito importante. Como então entender o fato de que existem vidas que importam mais do que outras, e que existem vidas que não importam absolutamente nada?

\footnotetext{
"Os comportamentos de cidadania", escreve Diana Taylor, "gênero, etnia e identidade sexual, por exemplo, são ensaiados e reproduzidos diariamente na esfera pública, consciente ou inconscientemente. Nesse caso, poderíamos dizer que caminhar em vias públicas pode ser entendido como performance de gênero, por exemplo, uma vez que $o$ ser humano internaliza modelos de comportamentos socialmente adequados e os reproduz de várias maneiras" (TAYLOR, 2011, p.11)
}

Uma performance artística atua de forma desestabilizadora tornando a performatividade cotidiana consciente. Ocorrências de racismo, classismo, homofobia, machismo constituem uma dimensão dessa ordem social e da violência naturalizada que serve à produção e controle desse modo de vida. Isso requer ser "protegido" não apenas das formas desprovidas de existência social, mas também da violência exercida sobre os "não favorecidos". Quando o agente da violência é a polícia, fica explícito que é a violência da ordem 
social. Portanto, além da punição que a repressão policial exerce sobre os corpos, é preciso refletir a fúria dissimulada da ordem social em tempos de normalidade, formas de violências cotidianas que já se expressam na linguagem da discriminação. Não é possível tentar anular a representação na arte para fazer entrar a violência "em ação" quando esta vem justamente da representação. A violência da linguagem em cena é exercida a partir de uma fronteira que não pode ser definida simplesmente como social, racial ou sexual, mas como uma fronteira da qual a dor do outro é desconhecida (como poderia ser o que acontece dentro de prisões, abrigos de menores, territórios populacionais em situação de marginalização etc.), não por mera indolência ou indiferença, mas porque é inerente à "ordem social" a descontinuidade entre os "favorecidos" e os demais, habitantes de territórios do não-ser (tomando a expressão de Fanon).

Na peça teatral HP, de Luis Barrales, a "diretora" (personagem) exige que o "ator" (personagem) tome medidas para interpretar com verossimilhança o papel de Hans Pozo². O ator argumenta a seriedade com que assumiu esta caracterização:

\begin{abstract}
"Isso tinha que acontecer comigo. Então, se eu fosse interpretar um marginal, deveria estar mais magro/ a diretora fala cinco quilos a menos / o importante é a alma do personagem, digo / Então, faça sua alma ganhar peso, responde / como faz isso?/ Quer que eu faça? / baixo cinco quilos, sem problema, assim substituo sua fome real pela minha dieta com cereais, chá verde e vegetais, mas não consigo perder muito / não fez a dieta / sim, fiz / não fez o suficiente, falta muito / o quê?/ Falta a energia de um flayte / será simplesmente essa energia. Estou comendo alface há quatro semanas!/ não é isso / tanto faz / você deveria dar uma volta em marta brunett / você está louca? Por que você quer que eu vá a Marta Brunett?/ para te impregnar dessa energia / posso imaginar a energia, uma vez fui muito longe comprar psicotrópicos. Do carro, você pode ver muitas coisas/ talvez não seja o suficiente/ você realmente quer que eu seja desmembrado?/ disse o Artaud, tem que cortar a garganta / Não se inspirou em Brecht?/ é um sincretismo entre Brecht e Artaud/ quero ir embora/ você é nojento/ você chamou um ator/ vá tomar banho e volte/ só tem água fria no chuveiro!/ um verdadeiro flayte toma banho com água fria/ um verdadeiro flayte não toma banho/ "(7)
\end{abstract}

Feral afirma que "o acontecimento cênico (...) faz o real surgir no palco fora de qualquer representação, ilusão ou ficção cênica" (FERAL, 2016, p.19). Ou seja, o acontecimento aqui não é a supressão da representação, mas o seu surgimento, que parece romper o contrato que confrontava o espectador com

\footnotetext{
${ }^{2}$ A obra teve como base o caso de Hans Pozo, que foi abandonado pela mãe aos 4 anos, passou por vários lares adotivos, aos 16 anos se viciou em pasta base de cocaína, se prostituiu e, às vezes, trabalhava no setor da construção. Em 2006, foi assassinado aos 21 anos com dois tiros, seu corpo foi desmembrado pelo assassino, e as partes foram distribuídas em diferentes pontos da cidade. A extrema marginalidade de sua vida tem sido tema de várias obras (de teatro, cinema, literárias e visuais). Em um dos locais onde foram encontrados seus restos mortais, vizinhos ergueram um monumento de pedra ao qual hoje são atribuídos milagres.
} 
um espetáculo. Agora o espectador é "tocado" diretamente, não fica simplesmente protegido pelo cênico, que costuma atuar diante dele como uma tela, como um simulacro de uma "janela para o mundo". A construção teatral ao ser explicitada torna-se, de certa forma, "cúmplice" da alteridade social e cultural de Hans Pozo, em que o verossímil da marginalidade é um fator na produção dessa margem que viabiliza o teatro. A violência da linguagem no trecho citado atua no espectador com um poder incriminador de baixa intensidade:

No HP de Barrales, a violência da marginalidade se naturaliza nos sentidos da percepção:

\begin{abstract}
"'O mau cheiro pode ser distinguido. É um cheiro de umidade permanente. como de uma umidade que sai da medula dos próprios ossos e que vai passando por tudo. E um cheiro de catarro eterno que nasce em pulmões formados no frio. É um cheiro de perda de autoestima, é um cheiro que permeia tudo, e assim também o cachorro de uma casa pobre será um cachorro com cheiro de pobre. (...) O cheiro de pobre é um cheiro de sabão nas mechas duras do cabelo, o cheiro de pobre é muito parecido com o cheiro de vinho engradado, bife acebolado, madeira sem verniz, (...) o cheiro de pobre tem um cheiro das vans onde passageiros felizes viajam para Cartagena durante o dia ou para Cajón del Maipo, Salto del Laja, Fonte do Parque Florestal ou Laguna de la Quinta normal ${ }^{3 \prime \prime}(13)$
\end{abstract}

Nesse trecho, Barrales mostra uma espécie de fronteira de classe que em sua naturalização parece estabelecer "sem sujeito" moral ou socialmente responsável, quando os preconceitos e representações que servem à construção do verossímil na medida em que a discriminação social atua em ordem fisiológica. Nessa obra, a expressão "cheiro de pobre" não se refere simplesmente à materialidade de uma existência que se passa em meio a carências básicas, mas também é o cheiro de seus prazeres, de sua felicidade, de seu cotidiano; enfim, o cheiro de um "modo de ser", o cheiro que emite um modo de vida que os próprios "pobres" caracterizam como seu. No trecho do filme coreano "Parasitas" (Bong Joon-ho, 2019), um casal da alta burguesia fala sobre o cheiro desagradável dos corpos dos criados que frequentam a casa. Quando a tragédia finalmente estala, em um momento de máxima violência e humor negro, o chefe da família faz um gesto de desprazer tapando o nariz diante do cadáver de um dos "invasores": o "cheiro da pobreza" é mais desagradável para ele do que ver sangue

As palavras no palco têm um resultado performativo? É a linguagem que ataca o espectador, quando as palavras adquirem a gravidade do corpo e do acontecimento, pois no ato de sua enunciação confrontam o espectador com uma representação que atua como uma fronteira. "Os pobres" constituem aquela parte da sociedade que tornou as condições habitáveis, é por isso que nunca poderiam sair de "lá", porque fazer do não-mundo um mundo lhe conferem "identidade", a marginalidade social como marca de identidade. Acontecendo no palco, as palavras de discriminação social atingem justamente a fronteira do

\footnotetext{
${ }^{3}$ Refere-se a locais populares de lazer.
} 
entendimento que torna possível falar da violência, condená-la, explicá-la, justificála, como se pudesse falar sobre isso. A violência abordada na peça altera e inverte o quadro da representação na mesma medida em que o sentido das palavras é ultrapassado pela gravidade de sua ocorrência cênica. Isso implica não só a insubordinação do significante, mas o fato de que a palavra que indica, descreve e qualifica é algo que alguém faz ao outro: captá-lo na representação que faz da carência um modo de vida que se fecha em si mesmo.

As palavras no palco têm um resultado performativo? É a linguagem que ataca o espectador, quando as palavras adquirem a gravidade do corpo e do acontecimento, pois no ato de sua enunciação confrontam o espectador com uma representação que atua como uma fronteira. "Os pobres" constituem aquela parte da sociedade que tornou as condições habitáveis, é por isso que nunca poderiam sair de "lá", porque fazer do não-mundo um mundo lhe conferem "identidade", a marginalidade social como marca de identidade. Acontecendo no palco, as palavras de discriminação social atingem justamente a fronteira do entendimento que torna possivel falar da violência, condená-la, explicá-la, justificála, como se pudesse falar sobre isso. A violência abordada na peça altera e inverte o quadro da representação na mesma medida em que o sentido das palavras é ultrapassado pela gravidade de sua ocorrência cênica. Isso implica não só a insubordinação do significante, mas o fato de que a palavra que indica, descreve e qualifica é algo que alguém faz ao outro: captá-lo na representação que faz da carência um modo de vida que se fecha em si mesmo.

A representação e a informação sobre a catástrofe social, política e histórica de uma sociedade têm uma espécie de "perda de perspectiva" do cotidiano; pode-se dizer que, de certa forma, mostram que a catástrofe e o cotidiano corresponderiam, cada um, a ordens de coisas incomensuráveis entre si. Os meios de comunicação permitem a circulação da catástrofe nos circuitos de consumo diário de unidades de informação e imagens. A performance, por outro lado, faz com que o próprio cotidiano se manifeste como território da catástrofe. Aqui se estabelece uma relação diferente com o cotidiano na performance, uma relação não cotidiana. Segundo Feral, "a força performativa do discurso não passa (ou passa pouco) aqui pelas palavras, que são quase inexistentes. Uma nova relação se estabelece com os objetos do cotidiano (paredes, sons, canções) que desloca a experiência da catástrofe em cada um e a ativa novamente" (FERAL, 2016, p.107-108). A proposta de performance transcende a contingência política e social dos acontecimentos, ou seja, transcende o imediatismo dos fatos, e é exatamente isso que a mediação e a representação requerem como recurso de pensamento. Aqui isso não se refere à análise "informada" ou reflexão de hipóteses, mas ao pensamento que oprime quando a emergência do real questiona os códigos naturalizados de percepção e compreensão de nossa experiência. Neste sentido, o próprio lugar do espectador é questionado quando por um momento ele deixa de assistir a um espetáculo que se passa diante dele para ser levado para o que acontece em sua própria subjetividade, quando entende aquilo que não entende. O espectador é dominado pelo real como um conflito interno que se aloja no mundo em que vive. O que chamamos de "mundo" é 
uma ordem de experiência estabelecida como invisibilidade e insonorização do mundo que contém uma espécie de problema sem solução. Isso não significa que o mundo não tenha solução, mas que esta não faz parte do mundo como o conhecemos. Nesse sentido, a forma sujeito que nos permite compreender um mundo em conflito está abalada, a performance dá origem ao chamado pensamento dominante.

Diante do exposto, como compreender as representações performativas nas práticas artísticas quando estas se propõem a influenciar, de alguma maneira, a forma como os indivíduos percebem e agem no presente? A performance pode ter um desempenho adequadamente político? Neste ponto, pode-se propor que o significado da performance não é político (pelo menos no sentido em que geralmente é entendido) precisamente porque se propõe a alterar uma forma de se relacionar com a realidade, uma forma que é política na medida em que expressa uma ordem do mundo que contém relações de força. Nesse sentido, a performance (como artifício, construção, encenação) traz à tona o político, isto é, as tarefas pendentes e os conflitos da política. A seguir será exposto brevemente essa hipótese e o problema que surge daí.

Existe um conceito de político essencialmente relacionado com o conflito como algo que seria inerente à sociedade humana. Chantal Mouffe aponta: "compreendo 'político' como a dimensão do antagonismo que considero constitutiva das sociedades humanas, enquanto entendo 'política' como o conjunto de práticas e instituições através das quais uma determinada ordem é criada, organizando a coexistência humana no contexto de conflito derivado do político" (MOUFFE, 2007, p.16). A partir daqui, desenvolve-se uma crítica ao capitalismo que, sob a ideia dominante de democracia liberal (com ênfase nos interesses individuais), teria transformado a política em uma questão meramente de procedimento, tornando o conflito um tema para especialistas. Isso, sem dúvida, está relacionado ao fato da progressiva autonomia da economia financeira, que a longo prazo resulta no processo de despolitização da sociedade. Assim, trataria de recuperar o conflito - "o político" - como algo essencial à organização social do ser humano. Nessa perspectiva, pode-se dizer que o "político" precede a "política" na medida em que esta consiste na entrada do conflito no fato social, inclusive seria até plausível pensar que o social é resultado do conflito; visto que este é exatamente o que relaciona os seres humanos entre si antes da institucionalidade, segundo a qual é possível aos indivíduos coexistirem "em contextos de conflito". Dessa maneira, existe política porque os indivíduos se encontraram e se relacionaram no regime de escassez e, portanto, de conflito antes de se organizarem (antes de estabelecerem pactos, acordos).

A política é a forma pela qual o ser humano se compromete a resolver seus conflitos sem recorrer à violência, ou seja, sem propor de fato a destruição do adversário. Entretanto, quando a performance atua como um recurso para pensar a violência nos termos indicados anteriormente, representa-se o fato de que a destruição já está aí incorporada estruturalmente à ordem política da sociedade. Portanto, nestes termos, a política seria a forma como se torna invisível o regime de destruição que originou a ordem social, ou talvez mais precisamente: a forma como 
posterga a irredutível emergência do conflito, pois "toda a ordem é política e se baseia em alguma forma de exclusão" (FERAL, 2016, p.25). Esse modo da política corresponderia à chamada "democracia liberal". Em nosso continente, a democracia foi saindo de governos ditatoriais, ou seja, a democracia tem sido a ideia que norteou o processo de saída de uma ditadura ou de uma guerra interna. A democracia não é uma ordem de coisas que os cidadãos esperam depois do terror, mas um começo para se construir na catástrofe. A transição da ditadura para a democracia foi o processo de institucionalização do neoliberalismo, o que implicou na legitimação de outro tipo de violência. As práticas artísticas podem influenciar o conflito, envolver-se, por exemplo, na proposta de um sentido político para a performance e seu questionamento da representação? Como exemplo da complexidade do problema, vamos ao seguinte caso.

A peça teatral "Noche Mapuche", escrita e dirigida por Marcelo Leonart, aborda o conflito entre o povo Mapuche e o Estado chileno, no contexto da violência na região de Araucanía, entre os ataques incendiários contra propriedades, equipamentos industriais e proprietários da área e a repressão policial aos membros da comunidade mapuche, acusados de tais ataques. No final da peça, uma das atrizes se posiciona no centro do palco e com a frase "isso não é um sonho, é a realidade" anuncia a encenação do que teria sido o confronto entre os membros da comunidade mapuche e o casal Luchsinger-Mackay. Este é um incidente que realmente aconteceu na madrugada de 4 de janeiro de 2013. É encenado o encontro entre Werner Luchsinger e os supostos membros da comunidade. De repente, a mesma personagem que iniciou esta simulação interrompe a cena dizendo: "o relato a seguir não faz parte de um relato vago, é uma chamada que a Central 133 de Carabineros de Chile recebeu de uma mulher, Vivianne Mackay, à 1 h15 minutos, em pânico absoluto, que se dirigia ao policial de plantão nos seguintes termos". Nesse momento, ouve-se a gravação correspondente ao momento em que Vivianne Luchsinger, desesperada e angustiada, pede socorro à polícia, informando o endereço várias vezes porque seu marido levou um tiro. Depois, a mesma personagem declara: "O que aconteceu ou poderia ter acontecido foi o seguinte", e então um ator se passando por Wener Luchsinger atira nas costas daquele que personifica um membro da comunidade mapuche. A peça termina com a personagem que iniciou a simulação gritando: "(...) O sentimento é que se deve colocar fogo em tudo. Deve-se purificar tudo. Como se tudo fosse um sonho. Porque só o fogo e os sonhos podem nos iluminar", diz Zepeda.. "Traga os galões!" Na madrugada de 4 de janeiro de 2013, o casal Luchsinger-Mackay realmente morreu no incêndio em sua residência. Aqui emergem duas questões para reflexão. A primeira, o fato de a obra conter, em sua interpretação mais direta, o discurso "partidário" não só a favor do povo mapuche, mas também da violência como meio de luta. A segunda, o recurso ao registro de um momento de sofrimento real cujo desfecho da morte é conhecido pelo público.

Em relação à primeira questão, é preciso ter em mente que o tema central da obra é a violência desencadeada na região da Araucanía. Se entendermos que nesse conflito o "passo para a ação" dos envolvidos revela o 
caráter irredutível do conflito, a impossibilidade ou o esgotamento dos acordos (o colapso da "política", segundo o conceito de Mouffe), poderia dizer que a postura tomada pela obra corresponde a uma espécie de "passo para a ação" a partir da arte. Isso significaria a impossibilidade da arte confrontada com a facticidade da violência. Leonart, autor e diretor da obra, define essa "tomada de partido" em favor de "forças que ao longo da história foram oprimidas". Isso está diretamente relacionado ao objetivo de atingir o radicalismo por meio da obra, o que necessariamente implica a entrada do real em cena. Para tanto, se utiliza do áudio da gravação. Um crítico avaliou a utilização desse recurso como "um meio artístico e moralmente condenável" (LETELLIER, 2017). Já a atriz e pesquisadora teatral Monserrat Estévez destaca que certos elementos em "Noche Mapuche" tornam a própria encenação um ato de violência (ESTÉVEZ, 2020). O que é relevante para a questão abordada neste artigo não é o propósito de Leonart de usar a arte - neste caso o teatro - para expressar sua tomada de partido pessoal (a legitimidade desse propósito aqui não é abordada), mas a questão se o evento daquele fragmento de realidade (a gravação) não viria a sancionar a cena para além das intenções do autor, o limite do teatro. Não se pode afirmar aqui que esse limite existe e que esse acontecimento poderia expressá-lo, mas essa escolha traz à cena um limite que é estranho à arte. O autor da obra se posiciona por meio de um discurso político ao assumir um "contexto" de confronto irredutível, ciente de que o ativismo a partir da arte apela a critérios extra-artísticos de legitimidade (morais, políticos, históricos). Ao longo dos anos, o recurso da gravação nessa obra poderá continuar levantando as mesmas questões. Ao fazer da arte o lugar de enunciação pública de uma posição de princípio (portanto, não política no sentido que propusemos), a obra impõe um limite, a impotência da arte como tal, atuando como um meio de expressão pública de seu autor..

Conforme apontado no início deste texto, a hipótese central é que, ao lidar com a violência atual, as artes inevitavelmente enfrentam seus limites. 0 desafio é poder fazer desses limites um recurso para pensar a violência como ordem mundial. Isso pode constituir a possibilidade de iniciar uma transformação, ao contrário do que acontece nas práticas artísticas que estrategicamente "se rendem" à violência, encenando o que tem sido o triunfo irresistível do mal. Aqui ao longo deste texto se propôs a levantar uma discussão que seguirá aberta. 


\section{Referências}

BLUMENBERG, Hans: Naufragio con espectador. Paradigma de una metáfora de la existencia, Madrid, Visor, 1995.

BUTLER, Judith: "Vida precaria, vida digna de duelo", Introducción a Marcos de guerra. Las vidas lloradas. Buenos Aires, Paidós, 2010

CAMPIGLIA, María: Santiago Sierra y Teresa Margolles. Estética de la impotencia y el desencanto, Tesis Doctoral, Universidad de Barcelona, Facultad de Bellas Artes, marzo, 2015

DIÉGUEZ. Ileana: Cuerpos sin duelo. Iconografías y teatralidades del dolor, Monterrey - México, Universidad Autónoma de Nuevo León, 2016

ESTÉVEZ, Monserrat: Escenificaciones de la violencia en la puesta en escena (20172018): prácticas de lo autoinmune, Tesis de Magíster en Artes, mención Teo- ría e Historia del Arte, Departamento de Teoría, Facultad de Artes, Universidad de Chile, 2020.

FERAL, Josette: Teatro y violencia. ¿Una mediación imposible?, Santiago de Chile, Frontera Sur, 2016

HUYSMANS, Joris-Karl: Grünewald. El retablo de Isenheim [1905], Madrid, Casimiro, 2010

LETELIER, Jorge: Crítica de "Noche mapuche", en el sitio web CULTURIZARTE, 16 DE OCTUBRE DE 2017: https://culturizarte.cl/critica-de-noche-mapuche-un-discurso-delirante-y-torpe/

MOUFFE, Chantal: En torno a lo político, Buenos Aires: Fondo de Cultura Económica, 2007

SARTRE, Jean-Paul: San Genet comediante y mártir, Buenos Aires, Losada, 1967

SEGATO, Rita Laura: La escritura en el cuerpo de las mujeres asesinadas en Ciudad Juárez, Buenos Aires, Tinta Limón, 2013

TAYLOR, Diana: Introducción a Estudios avanzados de performance, Diana Taylor y Marcela Fuentes eds., México, Fondo de Cultura Económica, 2011

ZÚÑIGA, Rodrigo: Estética de la demarcación. Ensayo sobre el Arte en los límites del Arte, Ediciones Programa de Magíster en Teoría e Historia del Arte, Facultad de 
Artes, Universidad de Chile, 2010 